\title{
Analysis for Transient Deliverability of Horizontal Wells
}

\author{
Y. M. Pang ${ }^{1, *}$, M. F. Li ${ }^{2}$, Z. H. Luo ${ }^{3}$, G. L. Zhang ${ }^{3, *}$ \\ ${ }^{1}$ Exploration and Development Research Institute, Daqing Oilfield Corp. Ltd., Daqing, Heilongjiang \\ 163712, China \\ ${ }^{2}$ Key Laboratory of Enhanced Oil and Gas Recovery of Ministry of Education, Daqing Petroleum \\ Institute, Daqing, Heilongjiang 163318, China \\ ${ }^{3}$ Oil Recovery Plant No.8, Daqing Oilfield Corp. Ltd., Daqing, Heilongjiang 163513, China \\ Email: yinhj7176@126.com
}

\begin{abstract}
Because the technology of horizontal wells can enlarge the contact area between well bores and oil reservoir, improve the reservoir flow behavior, and cnhance the oil recovery, horizontal well exploitation technology is being widely used by the petroleum industry. Recently, researches on the productivity of horizontal wells attracts more attention. But most of the researches are focused on steady production analyses, while researches on the transient deliverability are seldom. Thesefore, the governing equations are established by using source functions and the Newman product method, to calculate the transient deliverability of horizontal wells in the reservoir with infinite horizontal boundaries in this paper. By programming the equations, the curves of transient deliverability with different parameters can be given. The factors, which influence transient deliverability of horizontal wells, are discussed in detail.

On the basis of the research above, results are shown as follows:

(1) The main factors which influence the transient dilivertivity of horizontal wells conclude: length of horizontal wellbore, anisotropism, formation damage and the boundary conditions of the reservoir.

(2) The longer length a horizontal wellbore has, the higher productivity the horizontal well has. But taking economy into account, it doesn't mean that the longer length a horizontal well has, the better. Because when the length of horizontal wells is large enough, the increment of productivity becomes less. So there should be a best length for one horizontal well.

(3) Recearches show that the bigger the skin factor is, the less productivity the horizontal well has. So skin effect is the major factor that influences the transient deliverability of horizontal wells. And it is necessary to take effective measures to decrease the formation contaminant.

(4) The effect exerted made by anisotropism and boundary conditions shows that horizontal wells are fit for the reservoir with high vertical permeability, oil/water and oil/gas boundary.
\end{abstract}

\section{REFERENCES}

1. Li X P. Evolvement of both productivity and well test analysis for horizontal wells. Well Testing, 2003, 12(1): 62-65(in Chinese)

2. Joshi S D. Augmentation of well productivity with slant and horizontal well. Paper SPE 15375 , 1988: $729-739$

3. Sun C D, Zhang T Y, Zhou Y H, Shan C Y. Well test analysis of the horizontal well in daqing oilfield. Petroleum Instruments, 2004, 18(5): 1-4 (in Chinese) 